\title{
Standarisasi pencegahan body menabrak sliding door menggunakan metode poka yoke
}

\author{
Indrawan $^{1)^{*}}$, Muhammad Rusydi ${ }^{2)}$, Akhmad Satria Daris Jaya ${ }^{3)}$ \\ 1,2,3 Akademi Komunitas Toyota Indonesia, Kecamatan Telukjambe Barat, Kabupaten Karawang - 41361, \\ Indonesia. \\ indrawan@akti.ac.id*,rusydi@akti.ac.id, akhmadstria@akti.ac.id
}

\begin{abstract}
ABSTRAK
Kualitas adalah kesamaan dalam penggunaan barang guna untuk memenuhi kecukupan konsumen. Definisi dari kualitas sebagai pemenuhan kebutuhan konsumen, tanpa adanya cacat (ketidaksesuaian). Penelitian dan pengembangan ini dilakukan pada area kerja, bagian input surfacer, dan masalah yang terjadi adalah body menabrak sliding door. Teknik analisis data dilakukan dengan metode poka yoke pada wilayah berlangsungnya kecelakaan pada proses produksi. Metode tersebut direkomendasikan melalui penelitian dan pengembangan ini guna memperingati kepada pegawai (operator) untuk terhindar dalam ketidaksesuaian proses produksi. Pada tahap selanjutnya, adalah control dan monitor terhadap hasil analisis. Dengan tujuan proses body menabrak sliding door tidak terulang kembali. Maka ketika proses control dan monitor dilakukan dengan benar oleh pihak manajemen perusahaan maupun pegawai (operator) yang terintegrasi dengan masalah tersebut. Untuk itu penelitian atau pengembangan ini merekomendasikan guna dibuatkan lembar pemeriksaan pada periode pelaksanaan control dan monitor di tahap input surfacer.
\end{abstract}

Kata kunci: Control, Input surfacer, Monitoring, Poka Yoke.

\section{ABSTRACT}

Quality is the similarity in the use of the goods in order to meet the adequacy of the consumer. The definition of quality as the fulfillment of the needs of the consumer, without the presence of defects (nonconformities). Research and development is done on the work area, part of the input surfacer, and the problem that occurs is the body crashing into the sliding door. Data analysis techniques performed by the method of poka yoke in the territory of the ongoing accident in the production process. The method recommended through research and development in order to commemorate the employees (operators) to avoid non-conformities the production process. In the next stage, is to control and monitor the results of the analysis. The goal of the process of a body crashing into the sliding door is not reoccur. Then when the process control and monitor made properly by the management company and employees (operators) that are integrated with the matter. For that research or development is recommend in order to be made the examination sheet in the period of implementation of the control and the monitor is in the input stage surfacer.

Keywords: Control, Input surfacer, Monitoring, Poka Yoke.

diunggah: Oktober 2021, direvisi: Desember 2021, diterima: Desember 2021, dipublikasi: Desember 2021

Copyright (c) 2021 Indrawan, Muhammad Rusydi, Akhmad Satria Daris Jaya

This is an open access article under the CC-BY license

\section{PENDAHULUAN}

Kecacatan atau kerusakan merupakan permasalahan guna menurunkan hasil barang/produk dan kepuasan/kepercayaan terhadap konsumen (Bayers, 1997). Selain itu guna meningkatkan proses biaya yang semakin signifikan (Handoko, 1984). Oleh sebab itu proses produksi perlu memperhatikan kualitas guna kecacatan barang/produk dapat berkurang. Dikarenakan dapat memperbaiki pemborosan dari penggunaan bahan baku 
maupun biaya produksi (Purnomo, 2004). Maka harga barang/produk setiap jumlahnya dapat ditekan dan harga menjadi turun. Disebabkan kualitas adalah bagian dari perusahaan dalam bersaing dengan perusahaan lain (Hakim, 2006; Wisnu, 2013; Ustriaji, 2016). Selain itu dengan tujuan barang/produk berkualitas dengan harga standar di masyarakat umum. Sehingga perlu dilakukan pengendalian kualitas, dikarenakan implementasi dapat menjadikan pelanggan lebih menyakininya (Ariani, 2004). Maka kepuasan pelanggan bagian faktor yang perlu di pertimbangkan oleh perusahaan. Berikutnya jika kepuasan konsumen/pelanggan didapatkan dengan baik, maka konsumen/pelanggan akan memberikan dampak loyalitas terhadap barang/produk perusahaan (Besterfield, 1998). Tingkatan kualitas didapatkan melalui proses pengembangan, yaitu kegiatan perusahaan untuk mengembangkan added value. Dengan melakukan proses tersebut, maka perusahaan dapat mencukupi keinginan konsumen/pelanggan secara berkelanjutan (Gasperz, 1998). Selain itu perusahaan dapat disebut berkualitas oleh konsumen/pelanggan, jika memiliki sistem produksi yang tersistematis dan terkendali dengan terstruktur (Feingenbaum, 1992). Melalui pengendalian kualitas guna menghasilkan efektivitas dalam pencegahan terhadinya kecacatan barang/produk (Montgomery, 2009; Zhang, 2014). Sehingga hal ini dapat menekan berlangsungnya pemborosan dari faktor: penggunaan bahan baku dan tenaga kerja. Lean Six Sigma merupakan bagian dari metode pengendalian kualitas yang pada umumnya digunakan (Ulum \& Munir, 2019).

Metode poka yoke didasarkan dari Shigeo Shingo, berkisar pada tahun 1960-an. Maknanya berawal dari bahasa jepang, yang artinya poka (kesalahan yang tidak sengaja) dan yoke (pembuktian) (Hudori \& Josafat, 2017; Putra \& Sudiro, 2018; Putri \& Wiwik, 2019). Metode poka yoke didasarkan dari Shigeo Shingo, berkisar pada tahun 1960-an. Maknanya berawal dari bahasa jepang, yang artinya poka (kesalahan yang tidak sengaja) dan yoke (pembuktian). Gagasan yang mendasarnya guna merekomendasikan proses produksi, dengan tujuan agar kesalahan dapat diperbaiki dan dilakukannya pemberian rekomendasi yang sesuai. Selain itu dia juga pernah menjadi perwakilan dalam penelitian mengenai statistical process control di industri manufaktur jepang berkisar pada tahun 1950-an. Namun ternyata dengan pendekatan tersebut tidak dapat mengurangi kecacatan/kerusakan barang/produk perusahaan. Ketika melakukan kunjungan ke perusahaan lainnya, dia memberitahu mengenai permasalahan yang terjadi pada salah satu produk. Pada sisi produk tersebut merupakan swicth sederhana dengan dua push button yang terintegrasi dengan dua spring. Selain itu pegawai (operator) perusahaan tersebut biasanya melupakan tahapan/proses ketika perakitan berlangsung. Hal ini yang menjadi permasalahan sederhana ketika produksi, namun tidak sederhana ketika sudah sampai ke tangan pelanggan/konsumen. Permasalahan yang sering terjadi diperusahaan seperti: Sliding door di buka pada awal pekan di awal produksi; Proses produksi selama 1 minggu; Sliding door di tutup pada akhir pekan di akhir produksi; Aktivitas maintenance day; Sliding door tidak di buka pada awal pekan di awal produksi. Melalui jenis pendekatan kuantitatif dalam metode survei yang dilakukan, diketahui 5 permasalahan di atasyang dapat menyebakan kerusakaan atau cacat produk. Pada umumnya ketidaksesuaian tersebut dapat diketahui ketika barang/produk sampai ke tangan pelanggan/konsumen. Selanjutnya sebagai rasa tanggung jawab terhadap pelanggan/konsumen, perusahaan akan melakukan tindakan disassemble terhadap produk dan merakitnya kembali. Permasalahan tersebut dapat membuat perusahaan menjadi rugi biaya proses produksi, selain itu reputasi perusahaan dapat menurun. Bagian manajemen perusahaan perlu memperingati pegawai (operator) untuk lebih teliti pada saat berlangsung. Maka tujuan dari penelitian atau pengembangan ini akan mengimplementasikan metode tersebut dengan permasalahan yang sama dengan kasus di atas. Sehingga dapat meminimalkan terjadi kecacatan/kerusakan pada barang/produk perusahaan ketika proses produksi berlangsung (Nugraha, 2021). Maka penelitian atau pengembangan bertujuan guna 
menganalisis strategi dalam mengurangi tingkat kecacatan/kerusakaan kegiatan proses produksi pada input surfacer (sliding door) melalui metode poka yoke.

\section{METODE}

Poka yoke bagian metode yang menggunakan alat lain (sensor) atau memodifikasi mesin guna mengetahui ketidaksesuaian yang dilakukan oleh pegawai (operator) (Budiani, et al., 2020; Burlikowska \& Szewieezek, 2009). Selain itu umumnya digunakan agar memperbaiki terjadinya ketidaksesuaian yang dilakukan oleh pegawai (operator). Maka tujuan dari metide tersebut agar menghasilkan zero defect. Terdapat 3 kegunaan metode tersebut sebagai berikut (Djunaidi \& Pahlevi, 2021):

1. Control Methods, ketika berlangsungnya kegiatan produksi yang abnormal. Maka tindakan yang tepat adalah dengan mematikan mesin (kunci klem) guna mendiamkan proses operasi yang berlangsung. Hal ini guna mencegah terjadinya kecacatan/kerusakan secara terus-menerus. Bagian ini mempunyai banyak kegunaan jika dibandingkan warning methods yang lain dan dapat mencapi zero defect.

2. Warning Methods, dilakukan melalui pengaktifan peringatan melalui alarm atau benda lain yang dapat menghasilkan bunyi, cahaya dan lainnya (Thareja, 2016). Kecacatan/kerusakan dapat berlangsung secara terus-menerus jika pegawai (operator) tidak mengawasi peringatan tersebut.

3. Modification Methods, bertujuan untuk mengganti/memodifikasi benda/mesin yang digunakan untuk proses produksi. Sehingga kecacatan/kerusakan yang umumnya terjadi dapat berkurang dan benda/mesin tidak membuat kecacatan/kerusakan kembali. Pada umumnya pegawai (operator) yang tidak berkonsentrasi dapat membuat ketidaksesuaian, pada akhirnya dapat menimbulkan barang/produk menjadi cacat/rusak (ditambah ketika berlangsungnya mesin rusak (breakdown)). Namun terkadang pegawai (operator) tidak dapat dikatakan penyebab kesalahan sepenuhnya (Singh \& Archana, 2017; Diedrich \& Jansen, 2017). Melainkan dapat disebabkan oleh sistem yang tidak sesuai prosedur, sehingga hal ini menyebabkan pegawai (operator) sulit untuk memahaminya. Maka modification methods dapat membuat mudah pegawai (operator) dalam menjalankan tugasnya, karena sistem mesin berjalan sesuai dengan kebutuhan. Selain itu metode poka yoke terdapat 3 prioritas sebagai berikut (Hartanto, 2013; Hartini \& Bagus, 2010):

a. Contact Methods, pada dasarnya terdapat beberapa bagian dari alat yang digunakan (misalnya sensor). Hal ini guna untuk mengetahui/mendeteksi ketika proses produksi berlangsung abnormal.

b. Fixed-Value Methods, digunakan ketika kegiatan berlangsung pada waktu yang sama. Bagian ini dapat dikatakan sederhana, yaitu memberikan izin kepada pegawai (operator) untuk keluar ketika kegiatan di waktu yang sama berlangsung.

c. Motion-Step Methods, bagian ini dapat membantu proses produksi. Diperlukan beberapa kegiatan yang berbeda-beda dalam satu tahapan yang sedang dilakukan pegawai (operator). Selain itu sama dengan saat fixed-value methods di atas, yaitu pegawai (operator) bertanggungjawab terhadap kegiatan yang berbeda-beda. Namun sebagai gantinya dapat menindaklanjuti kegiatan proses produksi yang berbeda lainnya (Gasperz, Vincent. Lean Sigma Approach. Jakarta: Erlangga, 2005). 
Penelitian atau pengembangan didasarkan ketika melakukan tindakan studi lapangan di perusahaan (saat proses produksi berlangsung). Selanjutnya dilakukan studi literatur guna guna mengetahui implementasi metode yang sesuai dengan permasalahan di perusahaan. Pengumpulan dan pengambilan data penelitian menggunakan sebagain dari studi lapangan (wawancara dan dokumentasi). Setelah itu didapatkan metode yang sesuai untuk permasalahan yang terjadi, yaitu metode poka yoke. Maka tahap berikutnya dilakukan pembuatan diagram alur penelitian dan pengembangan pada Gambar 1.

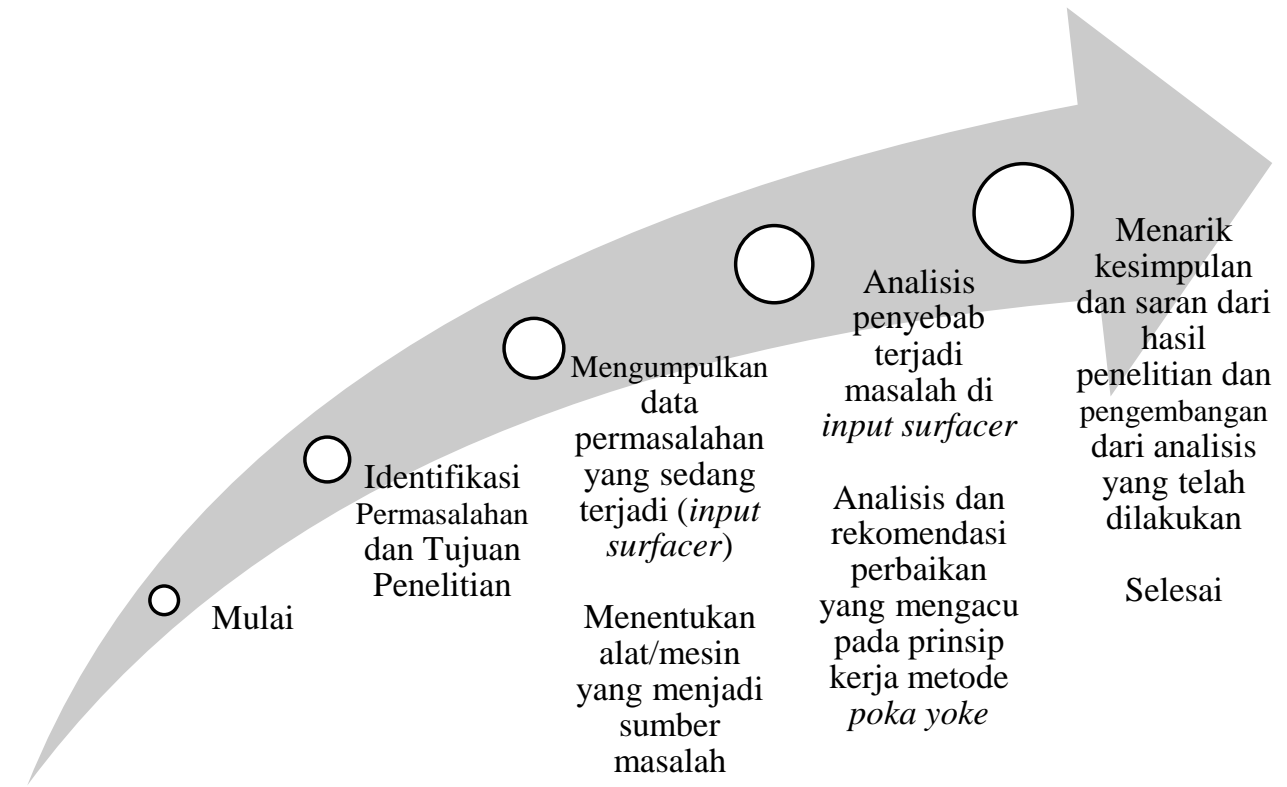

Gambar 1. Diagram alur penelitian dan pengembangan

\section{Variabel dan definisi operasional penelitian dan pengembangan}

Melakukan identifikasi masalah berdasarkan tujuan penelitian dan pengembangan untuk mencegah body menabrak sliding door di input surfacer. Hal ini dikarenakann terjadinya permasalahan yang tidak sesuai dengan standar pekerjaan. Hasil penelitian dan pengembangan menunjukan terdapat 1 permasalahan utama.

\section{Populasi dan teknik penentuan sampel}

Populasi/objek yang ditentukan yaitu body atau bagian dari mobil. Body mobil yang diproduksi di input surfacer, dari hasil survei yang dilakukan diketahui 38 unit dari 100 unit/harinya terjadi permalasahan di atas. Maka teknik penentuan sampel menggunakaan purposive sampel. Purposive sampel merupakan penentuan sampel melalui cara pertimbangan yang ditentukan. Hal ini dikarenakan unit yang ditentukan adalah yang tidak sesuai/cacat pada produknya. Sehingga dengan teknik penentuan sampel tersebut telah sesuai dengan penelitian yang dilakukan.

\section{Metode pencarian dan pengumpulan data}

Dalam melakukan metode pencarian dan pengumpulan data. Melakukan studi pustaka untuk mencari referensi sebagai parameter dalam melakukan penelitian dan pengembangan. Selain itu studi lapangan untuk mengetahui kondisi eksisting yang terjadi dalam kegiatan/aktivitas produksi produk.

\section{Teknik analisis data}

Teknik analisis data digunakan melalui metode yang telah ditentukan sebagai berikut: dilakukan pada wilayah yang umumnya terjadi kecelakaan pada saat proses produksi. Maka 
dari penelitian atau pengembangan memberikan rekomendasi guna memperingati pegawai (operator) agar terhindar dari ketidaksesuaian pada proses produksi berlangsung. Selanjutnya dilakukan tahap control dan monitor dari hasil yang didapatkan sebelumnya. Dilakukan guna memperbaiki proses produksi pada saat body menabrak sliding door yang tersistematis dan terorganisir dengan baik. Maka ketika tahap control dan monitor perlu menjadi peringatan untuk pihak manajemen perusahaan, selain itu partisipasi dari pegawai (operator) yang menjalankan tugasnya. Selanjutnya dari penelitian atau pengembangan ini memberikan rekomendasi agar dibuatkan lembar pemeriksaan (checksheet). Hal tersebut dilakukan ketika tahap control dan monitor sedang berlangsung untuk bagian input surface.

\section{HASIL DAN PEMBAHASAN}

Sebagai hasil dari penelitian atau pengembangan yang dilakukan pada area kerja pada bagian input surfacer dan masalah yang terjadi adalah body menabrak sliding door. Selanjutnya dilakukan wawancara/pengamatan dengan salah satu pekerja. Maka berikut ini merupakan alur sistem kerja yang terjadi permasalahan pada Gambar 2.:

\section{Sliding Door di buka pada Awal Pekan di awal Produksi}

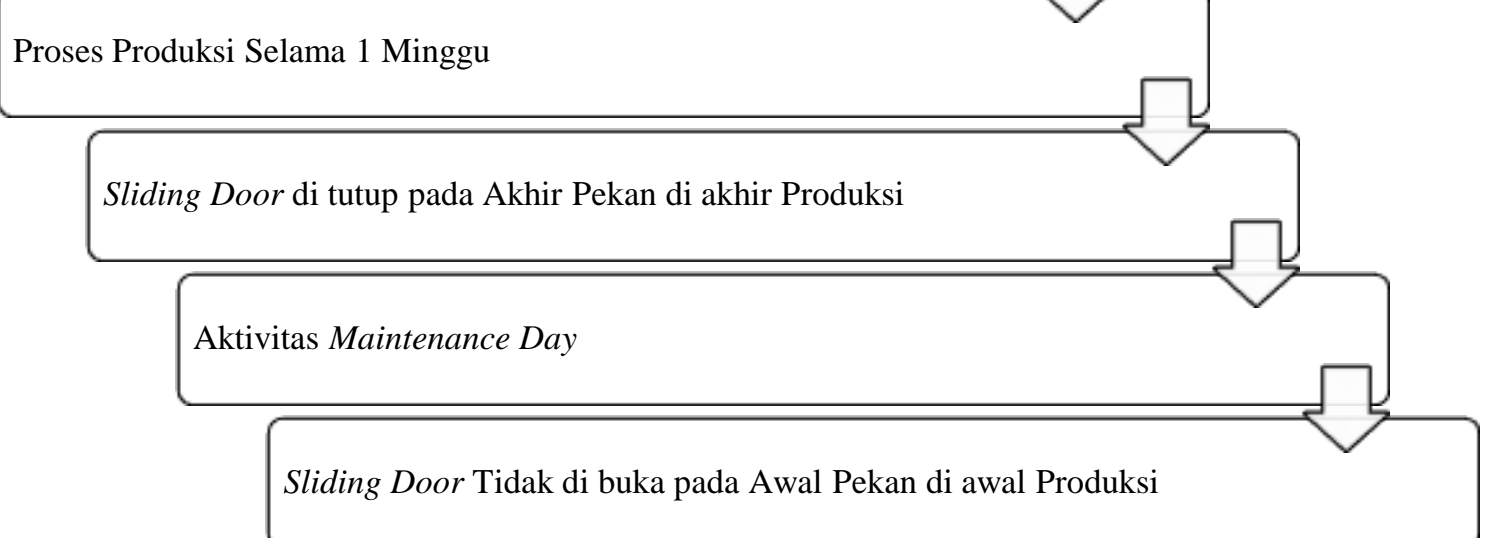

\section{Gambar 2. Alur permasalahan sistem kerja yang terjadi}

Hasil analisis dari Gambar 2. di atas perlu diperbaiki menggunakan metode poka yoke. Berikut hasil masing-masing analisis yang dilakukan:

1. Rencana Perbaikan Mengatasi Body Menabrak Sliding door, tahapan pengembangan dapat dilakukan untuk menangani permasalahan di atas pada Tabel 1.:

Tabel 1. Langkah perbaikan untuk mengatasi body menabrak sliding door

\begin{tabular}{|c|c|c|c|c|}
\hline No. & Faktor & $\begin{array}{l}\text { (What) } \\
\text { Apa Rencana } \\
\text { Perbaikan? }\end{array}$ & $\begin{array}{c}\text { (Why) } \\
\text { Mengapa Perlu } \\
\text { Diperbaiki? }\end{array}$ & $\begin{array}{c}(\text { How }) \\
\text { Bagaimana Cara } \\
\text { Perbaikan? }\end{array}$ \\
\hline 1. & Man & $\begin{array}{l}\text { Standarisasi } \\
\text { Kemampuan Operator } \\
\text { dalam Penggunaan } \\
\text { Mesin }\end{array}$ & $\begin{array}{l}\text { Terjadi Defect Produk } \\
\text { atau Not Good (NG) }\end{array}$ & $\begin{array}{l}\text { Membuat Pelatihan } \\
\text { yang Sesuai dengan } \\
\text { Penggunaan Mesin }\end{array}$ \\
\hline 2. & Material & $\begin{array}{ll}\text { Pemeriksaan } & \text { Bahan } \\
\text { Baku yang } & \text { Sesuai } \\
\text { Standarisasi } & \\
\text { Perusahaan } & \end{array}$ & $\begin{array}{l}\text { Terjadi Ketidaksesuaian } \\
\text { Proses Produksi }\end{array}$ & $\begin{array}{l}\text { Informasi terhadap } \\
\text { Departemen lain untuk } \\
\text { dilakukan Inspeksi }\end{array}$ \\
\hline 3. & Machine & $\begin{array}{lr}\text { Sliding } & \text { door } \\
\text { Memerlukan } & \text { Floor } \\
\text { Conveyor Auto } & \text { dalam }\end{array}$ & $\begin{array}{l}\text { Terjadi Penambrakan } \\
\text { Body di Sliding door }\end{array}$ & $\begin{array}{lr}\text { Membutuhkan } & \text { Floor } \\
\text { Conveyor Auto dalam } \\
\text { Menutup }\end{array}$ \\
\hline
\end{tabular}




\begin{tabular}{|c|c|c|c|c|c|}
\hline \multirow[t]{2}{*}{ No. } & \multirow[t]{2}{*}{ Faktor } & $\begin{array}{c}\text { (What) } \\
\text { Apa Rencana } \\
\text { Perbaikan? }\end{array}$ & \multirow[t]{2}{*}{$\begin{array}{c}\text { (Why) } \\
\text { Mengapa Perlu } \\
\text { Diperbaiki? }\end{array}$} & \multicolumn{2}{|c|}{$\begin{array}{c}\text { (How) } \\
\text { Bagaimana Cara } \\
\text { Perbaikan? }\end{array}$} \\
\hline & & $\begin{array}{l}\text { Menutup atau } \\
\text { Membuka }\end{array}$ & & Membuka & \\
\hline 4. & Method & $\begin{array}{l}\text { Memperbaiki Cara } \\
\text { Kerja dengan Prinsip } \\
\text { Poka Yoke }\end{array}$ & $\begin{array}{l}\text { Terjadi Kerugian } \\
\text { Produksi atau Not Good } \\
\text { (NG) }\end{array}$ & $\begin{array}{l}\text { Membuat } \\
\text { Pengawasan } \\
\text { Berkala }\end{array}$ & $\begin{array}{l}\text { Jadwal } \\
\text { Secara }\end{array}$ \\
\hline 5. & Environment & $\begin{array}{l}\text { Perawatan Berkala } \\
\text { Sekitar Bagian Sliding } \\
\text { door }\end{array}$ & $\begin{array}{l}\text { Terjadi Kerusakan } \\
\text { Teknis Sliding door }\end{array}$ & $\begin{array}{l}\text { Membuat } \\
\text { Perawatan } \\
\text { Berkala } \\
\end{array}$ & $\begin{array}{r}\text { Jadwal } \\
\text { Secara }\end{array}$ \\
\hline
\end{tabular}

2. Metode poka yoke bagian metode guna mengurangi/menghilangkan terjadinya kecacatan/kerusakan pada barang/produk yang dihasilkan. Dilakukan di wilayah yang umumnya terjadinya kecelakaan pada proses produksi. Selain itu yang direkomendasikan melalui penelitian dan pengembangan ini untuk memperingati kepada pegawai (operator), dengan tujuan terhidar dari ketidaksesuaian pekerjaan pada proses produksi berlangsung. Hasil rekomendasi pada Tabel 2.

Tabel 2. Poka yoke untuk rekomendasi perbaikan body menabrak sliding door

\begin{tabular}{|c|c|}
\hline Area Process & Peringatan \\
\hline & Input surfacer \\
\hline Machine & $\begin{array}{l}\text { Body terus berjalan walaupun pintu tertutup. Karena tidak ada interlock untuk stop } \\
\text { body jika sliding door tertutup. } \\
\text { Rekomendasi: Membutuhkan floor conveyor auto dalam menutup dan membuka } \\
\text { sliding door dengan menerapkan prinsip kerja poka yoke. Selain itu melakukan } \\
\text { pelatihan dalam penggunaan mesin secara berkala kepada mp produksi. }\end{array}$ \\
\hline Method & $\begin{array}{l}\text { Sliding door di input surfacer belum dibuka. Karena mp produksi lupa membuka } \\
\text { sliding door di input surfacer. } \\
\text { Rekomendasi: Membutuhkan floor conveyor auto dalam menutup dan membuka } \\
\text { sliding door dengan menerapkan prinsip kerja poka yoke. Selain itu melakukan } \\
\text { pelatihan dalam penggunaan mesin secara berkala kepada mp produksi. }\end{array}$ \\
\hline
\end{tabular}

Pada tahap selanjutnya ketika proses control dan monitor berlangsung dari hasil analisis yang telah dilakukan. Maka perlu dengan keseriusan dari pihak manajemen perusahaan dalam melakukan penerapan secara berkelanjutan. Selain itu diperlukan partisipasi dari seluruh pegawai (operator) ketika menjalankan tugasnya. Control dan monitor pada proses produksi berlangsung dapat membantu/mengantisipasi terjadinya kecacatan/kegagalan hasil barang/produksi yang dihasilkan. Jika pada saat proses control dan monitor berlangsung di wilayah yang umumnya terjadi masalah tersebut. Maka untuk memperbaikinya secara parsial dan menemukan pemecahan masalah secara cepat dan sesuai. Sehingga hasil dari barang/produk yang cacat dapat diminimalkan kuantitasnya. Untuk itu hasil dari penelitian atau pengembangan memberikan rekomendasi agar dibuatkannya lembar pemeriksaan (checksheet) pada saat proses control dan monitor di bagian input surfacer berlangsung (Rahayu \& Bernik, 2020).

\section{SIMPULAN}

Sebagai hasil kesimpulan dari penelitian atau pengembangan diterapkan pada wilayah kerja di bagian proses input surfacer bagian sliding door. Maka didasarkan dari hasil studi lapangan yang telah dilakukan dengan pihak perusahaan secara langsung dengan pegawai (operator). Diketahui jenis salah satu permasalahan umum yang sering terjadi, yaitu conveyor (body) terus berjalan ketika saat sliding door di input surfacer sedang tertutup. Diperlukan metode yang sesuai dengan permasalahan tersebut, yaitu metode poka yoke. Pemberian rekomendasi dari penelitian dan pengembangan guna memperingati kepada pegawai 
(operator) agar terhindar dari ketidaksaesuain pada proses produksi berlangsung. Selanjutnya dilakukan proses control dan monitor dari hasil analisis yang telah dilakukan. Dengan tujuan agar proses pembaharuan ketika body menabrak sliding door dapat diimplementasikan dengan baik. Maka ketika proses control dan monitor perlu keseriusan dari pihak manajemen perusahaan maupun pegawai (operator) yang berhubungan dengan pekerjaan tersebut. Sebagai hasil akhir dari penelitian dan pengembangan yang telah dilakukan, maka rekomendasi yang diperlukan adalah dengan adanya lembar pemeriksaan (checksheet).

\section{DAFTAR PUSTAKA}

Ariani, D. W., 2004. Pengendalian Kualitas Statistik. Yogyakarta: Andi Offset.

Bayers, P., 1997. Apply Poka Yoke Devices Now to Eliminate Defects. Annual Quality Congress, LI(1), pp. 451-471.

Besterfield, D. H., 1998. Quality Control. New Jersey: Prentice-Hall Inc..

Budiani, B., Permana, F., Fadlisyah, H. \& Fauzi, M., 2020. Standarisasi Pelabelan Menggunakan Metode Poka Yoke untuk Menghindari Larutan Kadaluarsa. Profisiensi : Jurnal Program Studi Teknik Industri, VIII(2), pp. 105-115.

Burlikowska, M. D. \& Szewieezek, D., 2009. The Poka-Yoke Method as An Improving Quality Tool of Operation in the Process. Journal of Achievements in Materials and Manufacturing Engineering, XXXVI(1), pp. 95-102.

Diedrich, F. \& Jansen, K., 2017. Faster and Simpler Approximation Algorithms for Mixed Packing and Convering Problems. Theoretical Computer Science, III(1), pp. 181-204.

Djunaidi, M. \& Pahlevi, N. O., 2021. Application of the Poka Yoke Method in the Mix Packing Part Process to Control the Amount of Flow Out. OPSI : Jurnal Optimasi Sistem Industri, XIV(1), pp. 50-58.

Feingenbaum, A. V., 1992. Total Quality Control. In: Kendali Mutu Terpadu. Jakarta: Erlangga, pp. 50-62.

Gasperz, V., 1998. Total Quality Management. Jakarta: Gramedia Pustaka Umum.

Hakim, A. N., 2006. Manajemen Industri. Yogyakarta: Andi Offset.

Handoko, T. H., 1984. Dasar-Dasar Manajemen Produksi dan Operasi. Yogyakarta: BPFE.

Hartanto, C., 2013. Perancangan Metode Poka-Yoke pada Proses Layanan Toko Sejahtera Kendari. Calyptra : Jurnal Ilmiah Mahasiswa Universitas Surabaya, II(1), pp. 1-17.

Hartini, S. \& Bagus, A. F., 2010. Standarisasi Tata Letak Mesin dengan Metode Poka Yoke untuk Mereduksi Breakdown Mesin dan Cacat Botol. Jurnal Standarisasi, XII(1), pp. 99-110.

Hudori, M. \& Josafat, M. S., 2017. Poka Yoke untuk Pembuatan Palet Package Information di Bagian Shipping. Industrial Engineering Journal, VI(1), pp. 1-17.

Montgomery, D. C., 2009. Statistical Quality Control: A Modern Introduction. United States: Jhon Wiley and Sons, Inc.. 
Nugraha, B., 2021. Pengembangan Sumber Daya Manusia: Deskripsi Teoretis tentang Kinerja Pegawai, Penilaian Kinerja Pegawai dan Pemeliharaan SDM. Banyumas: CV. Pena Persada.

Purnomo, H., 2004. Pengantar Teknik Industri. Yogyakarta: Graha Ilmu.

Putra, A. \& Sudiro, S., 2018. Penerapan Pokayoke untuk Mencegah Misbinning pada Mesin Symtek-300 Handler. Teknobiz : Jurnal Ilmiah Program Studi Magister Teknik Mesin, VIII(1), pp. 48-54.

Putri, D. R. \& Wiwik, H., 2019. Zero Deffect pada Produksi Kantong Kraft Melalui Metode Poka Yoke di PT. Industri Kemasan Semen Gresik. Jurnal Mebis (Manajemen dan Bisnis), IV(1), pp. 38-48.

Rahayu, P. \& Bernik, M., 2020. Peningkatan Pengedalian Kualitas Produk Roti dengan Metode Six Sigma Menggunakan New \& Old 7 Tools. Jurnal Bisnis \& Kewirausahaan, pp. 128-136.

Singh, P. \& Archana, N., 2017. Optimization of Supply Chain System by Implementing Milk Run Logistics Method - An Implementation Paper. International Journal of Innovative Research in Science, Engineering and Technology, VI(4), pp. 5380-5490.

Thareja, P., 2016. Poka Yoke: Poking Into Mistakes for Total Quality!. Omni Science: A Multi-disciplinary Journal, VI(2), pp. 11-20.

Ulum, R. \& Munir, M., 2019. Implementasi Six Sigma dengan Pendekatan Poka Yoke guna Reduksi Bagian Case Packer pad PT. X. Journal Knowledge Industrial Engineering (KJIE), VI(1), pp. 11-23.

Ustriaji, F., 2016. Analisa Daya Saing Komoditi Ekspor Unggulan Indonesia di Pasar Internasional. Jurnal Ekonomi Pembangunan, XIV(2), pp. 139-150.

Wisnu, A. P., 2013. Quality Control: Panduan Penerapan Teknis. Bekasi: Wishnu AP \& Partners.

Zhang, A., 2014. Quality Improvement Through Poka-Yoke: From Engineering Design to Information System Design. International Journal of Six Sigma and Competitive Advantage, VIII(2), pp. 1-14. 